V. Verba, PhD

O. Zaporozhets, Dr.Sci.

I. Kucharenko, Stud

E. Kul'baka, Stud.,

National Taras Shevchenko University of Kyiv, Kyiv, Ukraine

\title{
SORPTION PRECONCENTRATION AND DETERMINATION OF ANTIMONY AND TELLURIUM ON MODIFIED SILICA GEL
}

Antimony and its compounds are widely used in industry, making it one of the priority pollutants of air and the aquatic environment. Excess of antimony is selectively concentrated in a thyroid gland, a liver, a spleen. The manifestation of the toxic effect of antimony is a variety of impaired functions of the human body, so the content of this element in drinking water normalizes is at the level of $5 \mu \mathrm{g} / \mathrm{l}$. Recently, tellurium has also been increasingly the subject of research by analyst chemists. Tellurium is a biologically active element and its concentrations in the environment are strictly regulated. According to sanitary rules and regulations, the maximum allowable concentration of tellurium in drinking water is 0.01 mg/l.

The article is devoted to the elaboration of solid-phase reagents based on the quaternary ammonium salt (QAS) immobilized on silica gel and to the development on this basis of sorption-spectrometric and visual test-methods of the determination of Sb(III) and Te(IV). The mechanism of the interaction between QAS immobilized on silica gel and the anions iodide complex of antimony and tellurium was studied. It was found that it proceeds by the ion-associative mechanism. Conditions of sorption preconcentration of anionic complexes of elements were optimized. For the quantitative sorption of antimony (III), the weight of the sorbent is $0.020 \mathrm{~g}$ and the volume of the solution is $25.0 \mathrm{ml}$. Under these conditions, the anionic complex is sorbed by $98 \%$. The maximum concentration ratio is $1.25 \mathrm{l} / \mathrm{g}$. The sorption equilibrium in the system is established in 20 minutes. For the quantitative extraction of tellurium (IV), the optimal weight of the sorbent is $0.050 \mathrm{~g}$ and a solution volume of $25.0 \mathrm{ml}$. Under these conditions, the degree of sorption reaches about $80 \%$. The maximum concentration ratio is $0.4 \mathrm{l} / \mathrm{g}$. The sorption equilibrium in the system is established in 15 minutes. The influence of foreign ions on the extraction degree of the investigated elements, and also on the magnitude of analytical signal, was studied. Sorptionspectrometric and visual test-methods of the determination of Sb(II) and Te(IV) in pharmaceutical preparation "Antimonium tartaricum" and "Tellurium Metalicum"

Keywords: solid-phase reagents, immobilization, silica gel, ionic associates, solid-phase spectrophotometry, test-methods, Sb(III), Te(IV), pharmaceutical preparations.

Удк 541.11

DOI: https://doi.org/10.17721/1728-2209.2019.1(56).4

Н. Головата, канд. хім. наук, golovatanataliya@gmail.com,

Н. Котова, канд. хім. наук,

Н. Усенко, канд. хім. наук,

Київський національний університет імені Тараса Шевченка, Київ, Україна

\section{МОДЕЛЮВАННЯ ТЕРМОДИНАМІЧНИХ ВЛАСТИВОСТЕЙ РОЗПЛАВІВ ПОтРІЙнОї СИСтЕМИ Ge-Mn-Gd}

Проаналізовано наявні та розраховано термодинамічні властивості рідких сплавів граничних подвійних систем, що утворюють потрійну Ge-Mn-Gd; визначено енереії Гіббса змішування рідких сплавів системи Ge-Mn-Gd. Для визначення активностей компонентів, енергій Гіббса змішування та ентальпій змішування рідких сплавів систем Ge-Mn(Gd), сплавоутворення яких супроводжується значним виділенням тепла, було застосовано модель ідеального асоційованого розчину. Для розплавів системи Mn-Gd, взаємодія в яких характеризується доволі незначними екзотермічними ефектами, використано модель регулярних розчинів. На базі отриманих для граничних подвійних систем концентраційних залежностей енергій Гіббса змішування визначено поверхню енергії Гіббса змішування розплавів потрійної системи Ge-Mn-Gd за моделлю регулярного розчину із залученням методу Редліха - Кістера - Мугеіану. Проведено порівняння отриманої топології проекиій ізоліній енергій Гіббса із визначеними нами раніше термохімічними властивостями рідких сплавів цієї системи. Порівняльний аналіз виеляду цих поверхонь у системі Ge-Mn-Gd дозволив зробити висновок, що поверхні $\Delta G$ і $\Delta_{m} H$ монотонно зменшуються у напрямку від манганового кута діаграми до сторони трикутника Ge-Gd. Мінімальному значенню термодинамічних характеристик змішування потрійних рідких сплавів відповідає склад, що збігається зі складом найбільш стійкого тугоплавкого інтерметаліду в системі Ge-Gd. 3 ходу ізоліній енергій Гіббса та інтегральних ентальпій змішування можна зробити також висновок про вплив упорядкування, яке існує в системі Ge-Mn при мольній частиі мангану більше 0,7, на властивості потрійних розплавів, розташованих поблизу иієї бінарної системи. Таким чином, топологія ізоліній та великі екзотермічні значення отриманих термодинамічних величин дозволяють зробити обґрунтований висновок про збереження в рідких сплавах системи Ge-Mn-Gd сильної міжчастинкової взаємодії між різнойменними компонентами, яка властива системі Ge-Gd у твердому стані.

Ключові слова: манган, гадоліній, германій, рідкі сплави, енергія Гіббса змішування, модель ідеального асоційованого розчину, модель регулярного розчину, метод Редліха - Кістера - Муггіану, ентальпія змішування.

Вступ. Рідкісноземельні інтерметалічні сполуки в потрійних системах RE-Mn-Ge (де RE - рідкісноземельний метал), зокрема $\mathrm{GdMnGe}, \mathrm{GdMn}_{2} \mathrm{Ge}_{2}, \mathrm{Gd}_{3} \mathrm{Mn}_{4} \mathrm{Ge}_{4}$ та $\mathrm{GdMn}_{6} \mathrm{Ge}_{6}[1-5]$, привертають значну увагу через їхні незвичайні електронні та магнітні властивості. Такі сполуки можуть виявляти антиферомагнітний характер упорядкування із переходом у феримагнітний, парамагнітний і навіть феромагнітний стан під впливом температурного чи магнітного поля або при заміщенні певної частини атомів сполуки атомами деяких інших d- та f-металів. Магнітні властивості вказаних інтерметалідів роблять їх перспективними для використання як магнітних матеріалів. Цікавими та перспективними магнітними матеріалами можуть бути аморфні матеріали, отримані зі сплавів системи Ge-Mn-Gd [6]. Тому інформація про термодинамічні властивості розплавів цієї системи може бути корисною для виробництва магнітних, магнетокалоричних та аморфних матеріалів.
Знання термодинаміки і фазових діаграм є вкрай важливим для матеріалознавчих досліджень як основа для розробки нових матеріалів, а також для управління технологічними процесами виробництва матеріалів.

Раніше у роботі [7] нами представлено калориметричний експеримент для рідких сплавів п'яти перерізів $x_{G e} / x_{M n}$ системи Ge-Mn-Gd при температурі 1830 K, а у роботі [8] інтегральні ентальпії змішування змодельовано в припущенні адитивності парних взаємодій із застосуванням методу Редліха - Кістера - Муггіану у всьому концентраційному інтервалі. Отримані величини найкращим чином відповідали наявним експериментальним даним. Також у [8] було запропоновано концентраційні інтервали, де можна очікувати легкого утворення аморфних фаз у цій потрійній системі. Проте інші термодинамічні характеристики для розплавів даної системи дотепер не визначено. 
Тому для більш повного розуміння природи міжчастинкової взаємодії в розплавах системи Ge-Mn-Gd нам у даній роботі було необхідно визначити активності компонентів, енергії Гіббса та ентальпії змішування рідких сплавів граничних подвійних систем $\mathrm{Ge}-\mathrm{Mn}(\mathrm{Gd}), \mathrm{Mn}-\mathrm{Gd}$ та потрійної Ge-Mn-Gd для всього складу концентрацій.

Об'єкти, методи та результати дослідження. Для визначення енергій Гіббса розплавів потрійної системи Ge-Mn-Gd необхідні відомості широкого спектра термодинамічних властивостей її граничних подвійних систем. Так, для обрахунку в системах $\mathrm{Ge}-\mathrm{Mn}(\mathrm{Gd})$ було застосовано метод ідеального асоційованого розчину (MIAP) за методикою, формалізм якої детально описано у нашій роботі [9]. Для системи Mn-Gd нами було використано модель регулярного розчину. Далі на підставі отриманих концентраційних залежностей енергій Гіббса змішування в розплавах граничних подвійних систем було визначено величини енергій Гіббса для рідких сплавів потрійної системи Ge-Mn-Gd у всьому концентраційному інтервалі із застосуванням формалізму Редліха - Кістера - Муггіану. Для цього нами було використано наведені нижче дані для граничних подвійних систем. Слід зазначити, що фразові діаграми всіх трьох граничних подвійних систем характеризуються існуванням значної кількості фраз змінного складу.

Ge-Mn. Термодинамічне моделювання на базі аналізу значної кількості наявних термодинамічних даних по цій системі проведено у роботі [10]. Автори змоделювали концентраційні залежності ентальпії змішування рідких сплавів системи Ge-Mn для двох температур, 1278 та 1580 К, і за висновками авторів ентальпія у розплавах цієї системи є температурнозалежною. Результати моделювання при 1580 К [10] практично збігаються із визначеними в [11] методом високотемпературної калориметрії при 1585 К ентальпіями змішування рідких сплавів системи Ge-Mn, тому далі ми використали саме дані [11]. Так, за [11] у розплавах системи Ge-Mn мінімум інтегральної ентальпії змішування $\left(\Delta_{m} H\right)$ становить 20,9 кДж моль ${ }^{-1}$ при $x_{\text {мn }}=0,65$. У роботі [12] методом ЕРС досліджено сплави від 0,127 до 0,755 мольної частки германію в інтервалі температур 1110-1320 К. Визначені величини термодинамічних характеристик відносяться до утворення рідких сплавів із твердого $\beta$ мангану та рідкого германію. Установлено, що для всієї області концентрацій ізотерма активності мангану характеризується великими від'ємними відхиленнями від ідеальних розчинів. Ізотерма активності германію в інтервалі складу $0<x_{M n}<0,25$ наближається до ідеальної, в іншій області концентрацій вона також виявляє значні від'ємні відхилення від ідеальної поведінки. Показано також, що у всій концентраційній області рідкі розчини Ge-Mn мають великі від'ємні величини надлишкових енергій Гіббса. Утворення рідких сплавів супроводжується значним виділенням тепла і зростанням ентропії. Екстремальні значення інтегральних надлишкових термодинамічних фрункцій лежать у інтервалі від 0,6 до 0,7 мольних часток мангану. Згідно із діаграмою стану саме в цій області $\left(x_{м n}=0,6 \div 0,8\right)$ виявлено ряд хімічних сполук [10].

Таким чином, для системи Ge-Mn температура для розрахунків за MIAP обрана рівною 1580 К. Для розрахунку енергій Гіббса змішування рідких сплавів системи Ge-Mn дані з активностей компонентів [12] було перераховано на зазначену температуру. Порівняльний аналіз концентраційних залежностей термодинамічних функцій [12] та діаграми стану системи Ge-Mn [10] дозволив зробити припущення про існування у розплавах цієї системи асоціатів складу $\mathrm{MnGe}$ та $\mathrm{Mn}_{2} \mathrm{Ge}$. Концентраційні залежності енергії Гіббса змішування розплавів системи $\mathrm{Ge}-$ $\mathrm{Mn}$ при $1580 \mathrm{~K}$ наведено на рис. 1, який демонструє задовільне узгодження між експериментальними та розрахованими за MIAP значеннями енергії Гіббса.

Параметри утворення асоціатів у рідких сплавах системи Ge-Mn наведено в табл. 1.

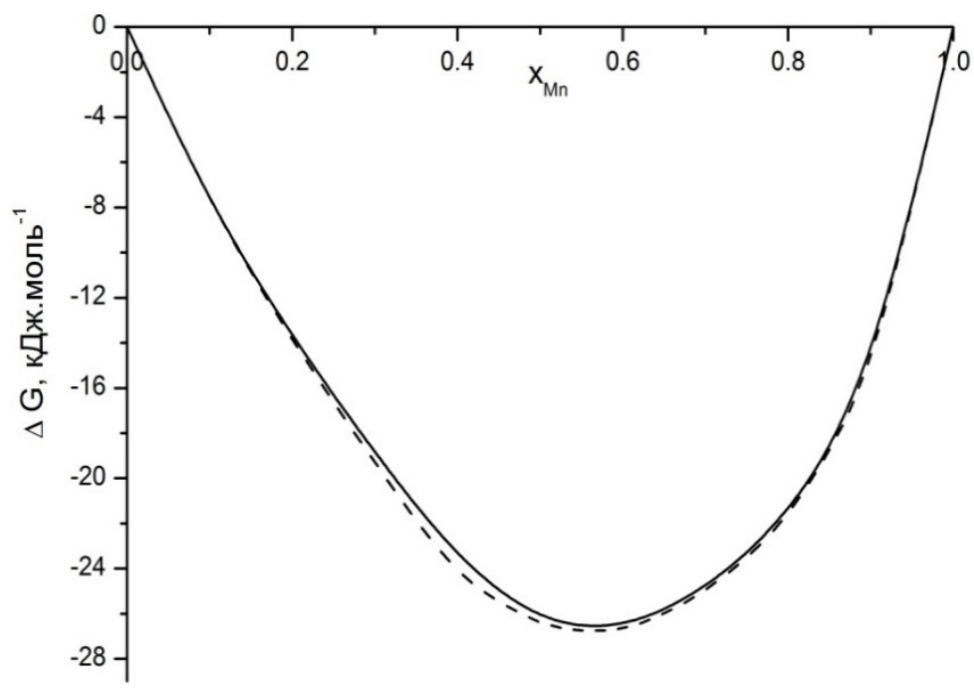

Рис. 1. Концентраційна залежність енергї̈ Гіббса змішування розплавів бінарної системи Ge-Мn при 1580 К, кДж·моль-1: суцільна лінія - експериментальні дані по $\Delta G$ [12], перераховані на 1580 К; пунктирна лінія - дані по $\Delta G$, розраховані нами за МIAP

Параметри утворення асоціатів у системах Ge-Mn при $1580 \mathrm{~K}$

Таблиця 1

\begin{tabular}{|c|c|c|c|}
\hline Система & Склад асоціатів & $\begin{array}{c}\text { Ентальпії утворення асоціатів, } \boldsymbol{\Delta} \boldsymbol{H}^{\boldsymbol{f}}, \\
\text { кДж.моль }\end{array}$ & $\begin{array}{c}\text { Ентропії утворення асоціатів, } \boldsymbol{\Delta} \boldsymbol{S}^{\boldsymbol{f}}, \\
\text { Дж.(моль·К }\end{array}$ \\
\hline \multirow{2}{*}{$\mathrm{Ge}-\mathrm{Mn}$} & $\mathrm{MnGe}$ & $-54,19$ & $-4,61$ \\
\cline { 2 - 4 } & $\mathrm{Mn}{ }_{2} \mathrm{Ge}$ & $-86,25$ & $-15,11$ \\
\hline
\end{tabular}

Ge-Gd. Термодинамічні дані про розплави цієї системи дуже обмежені, є відомості тільки про інтегральні ентальпії змішування рідких сплавів Ge-Gd, отримані при 1973 К [13] методом високотемпературної калориметрії. Так, мінімум $\Delta_{m} H$ досягає значної для рідких сплавів величини -98,4 кДж моль ${ }^{-1}$ в області концентрацій $x_{G e}=$ 
0,45, що дозволяє зробити висновки про наявність ближнього впорядкування за типом хімічної сполуки, оскільки поблизу цього складу, згідно з фазовою діаграмою [14], у твердому стані існує високотемпературна сполука $\mathrm{Gd}_{5} \mathrm{Ge}_{3}(2063 \mathrm{~K})$. Крім цього, германій та гадоліній у твердому стані утворюють ще кілька тугоплавких сполук. У нашій роботі розрахунки активностей гадолінію та германію проведено за координатами ліквідусу діаграми стану системи Gd-Ge за рівняннями Шредера та Хауфффе - Вагнера, описаними у [15]. Беручи до уваги, що активності компонентів характеризуються значним відхиленням від закона Рауля, а також великі від'ємні значення ентальпій змішування розплавів системи $\mathrm{Gd}-\mathrm{Ge}$, правомірно припустити, що сильна взаємодія між різносортними атомами зберігається при досить значних перегрівах над температурами ліквідусу. Таке припущення дозволило нам провести моделювання термодинамічних характеристик розплавів цієї системи (ентальпій та енергій Гіббса змішування) у рамках MIAP. Беручи до уваги діаграму стану системи Gd-Ge [14], дані про термодинамічні характеристики германідів гадолінію [16], а також вигляд кривих активностей компонентів, справедливим буде припущення про існування в розплавах системи поблизу лінії ліквідус асоціатів, які утворюються гадолінієм та германієм. Так, найкраще узгодження між кривими концентраційної залежності ентальпій змішування, отриманими за результатами експериментальних досліджень [13] та розрахованими за MIAP, досягається при проведенні обчислень із набором асоціатів такого складу: $\mathrm{GdGe}_{2}, \mathrm{GdGe}$ та $\mathrm{Gd}_{2} \mathrm{Ge}$. Проведено також розрахунки за MIAP значень енергії Гіббса змішування в системі Ge-Gd при 2100 К. Концентраційні залежності енергії Гіббса змішування рідких сплавів цієї системи наведено на рис. 2. На цьому ж рисунку наведено й концентраційну залежність енергії Гіббса змішування розплавів системи $\mathrm{Y}-\mathrm{Ge}$, розраховану за даними [17], оскільки ітрій та гадоліній виявляють дуже велику подібність фізико-хімічних властивостей, а також системи $\mathrm{Ge}-\mathrm{Gd}(\mathrm{Y})$ мають дуже схожі діаграми стану.

Параметри утворення асоціатів рідких сплавів системи Ge-Gd наведено в табл. 2.

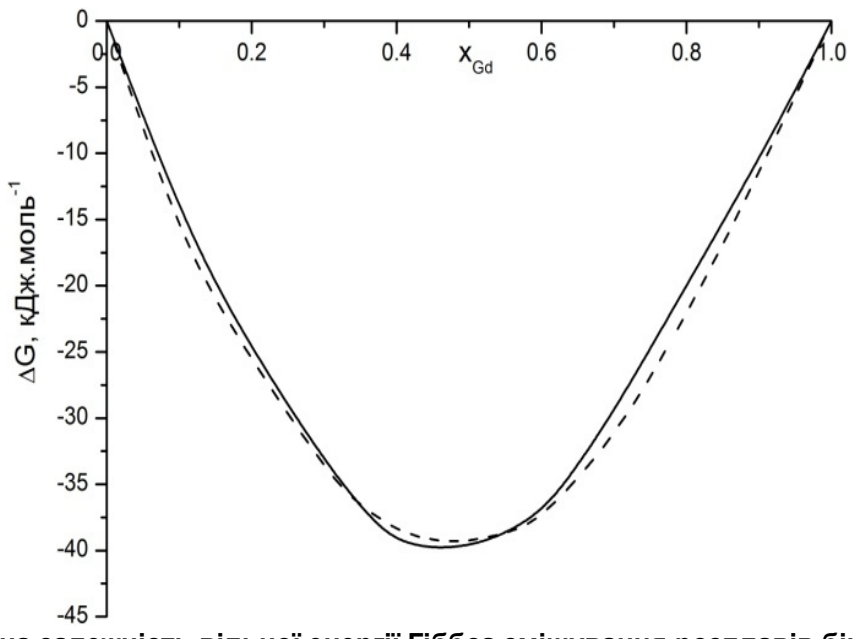

Рис. 2. Концентраційна залежність вільної енергії Гіббса змішування розплавів бінарних систем Ge-Gd (пунктирна лінія - наш розрахунок за MIAP) та Ge-Y (суцільна лінія - дані [17]) при 2100 К, кДж·моль-1

Параметри утворення асоціатів у системі Gd-Ge при 2100K

\begin{tabular}{|c|c|c|c|}
\hline Система & Склад асоціатів & $\begin{array}{c}\text { Ентальпії утворення асоціатів, } \Delta H^{f}, \\
\text { кДж·моль }{ }^{-1}\end{array}$ & $\begin{array}{c}\text { Ентропії утворення асоціатів, } \Delta S^{f}, \\
\text { Дж.(моль'К })^{-1}\end{array}$ \\
\hline \multirow[t]{3}{*}{ Ge-Gd } & $\mathrm{GdGe}_{2}$ & $-354,2$ & $-135,11$ \\
\hline & GdGe & $-199,25$ & $-74,10$ \\
\hline & $\mathrm{Gd}_{2} \mathrm{Ge}$ & $-166,39$ & $-46,01$ \\
\hline
\end{tabular}

Gd-Mn. У роботі [18] представлено критичний огляд наявних експериментальних термодинамічних даних для системи Gd-Mn, на підставі якого було проведено термодинамічне оцінювання системи з використанням методу CALPHAD. Для інтегральної ентальпії змішування було використано дані високотемпературного калориметричного експерименту для $1650 \mathrm{~K}$ із роботи [19]. При проведенні розрахунків температурну залежність ентальпій змішування рідких сплавів вважали незначною. У системі Gd-Mn ентальпії змішування - незначні від'ємні величини (екстремум $\Delta_{m} H=-2,0$ кДж'моль $\left.{ }^{-1} п р и x_{M n}=0,6\right)$ [19]. Згідно з діаграмою стану цієї системи [20] у ділянці концентрацій багатих на Mn сплавів існують три інтерметалічні сполуки, що плавляться за невисоких температур нижче температури плавлення мангану. Оскільки утворення сплавів системи $\mathrm{Mn}-\mathrm{Gd}$ супроводжується невеликими екзотермічними ефектами, то розрахунок енергій Гіббса змішування проведено за моделлю регулярного розчину.
Отримані значення енергії Гіббса змішування в системах Ge-Mn(Gd) та Mn-Gd було перераховано для температури 1830 К. Потім із використанням відомого формалізму Редліха - Кістера - Муггіану нами було визначено інтегральні енергії Гіббса змішування розплавів потрійної системи Ge-Mn-Gd при 1830 К для всього концентраційного інтервалу (рис. 3) (стан потрійних розплавів складу поблизу існування високотемпературного германіду германію в системі Ge-Gd слід розглядати як переохолоджений рідкий).

Для порівняння на рис. 4 наведено проекції змодельованих за моделлю регулярного розчину із застосуванням формалізму Редліха - Кістера - Муггіану ізоентальпій змішування розплавів потрійної системи $\mathrm{Ge}-\mathrm{Mn}-\mathrm{Gd}$ для всього концентраційного трикутника Гіббса за даними [8] (стан потрійних розплавів складу поблизу існування високотемпературного германіду германію в системі $\mathrm{Ge}-\mathrm{Gd}$ слід розглядати як переохолоджений рідкий). 


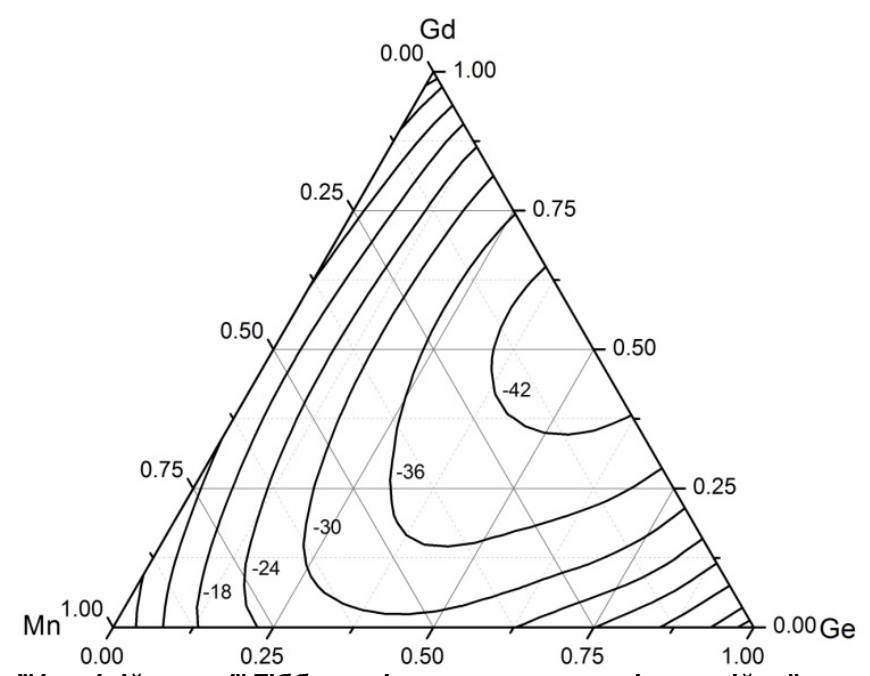

Рис. 3. Проекції ізоліній енергії Гіббса змішування розплавів потрійної системи Ge-Mn-Gd при 2100 К, кДж· моль ${ }^{-1}$

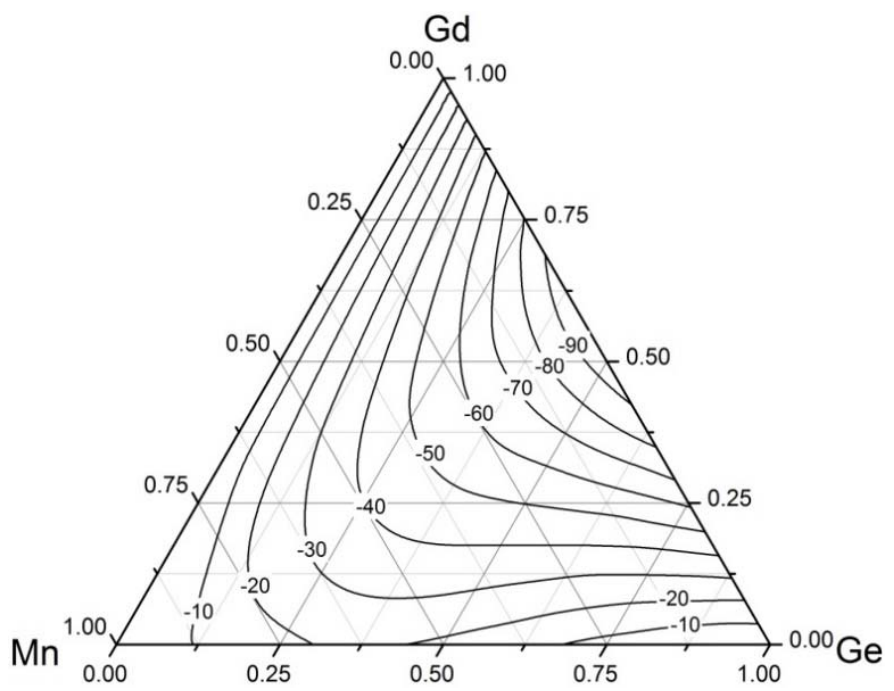

Рис. 4. Проекції ізоліній інтегральної ентальпії змішування розплавів потрійної системи Ge-Mn-Gd при 1830 К, кДж·моль ${ }^{-1}[8]$

Висновки. Порівняльний аналіз вигляду поверхонь $\Delta G$ (рис. 3) і $\Delta_{m} H$ (рис. 4) в системі Ge-Mn-Gd підтверджує висновки, які зроблені при аналізі поверхні $\Delta_{m} H$, а саме те, що поверхні і $\Delta G$, і $\Delta_{m} H$ монотонно зменшуються у напрямку від манганового кута діаграми до сторони трикутника $\mathrm{Ge}-\mathrm{Gd}$. Мінімальному значенню термодинамічних характеристик змішування потрійних рідких сплавів відповідає склад, що збігається зі складом найбільш стійкого інтерметаліду в системі Ge-Gd. 3 ходу ізоліній вільних енергій та інтегральних ентальпій змішування можна зробити також висновок про вплив упорядкування, яке існує в системі Ge-Mn при $x_{M n}>0,7$, на властивості потрійних розплавів, розташованих поблизу цієї бінарної системи.

Таким чином, топологія ізоліній та великі екзотермічні значення отриманих термодинамічних величин дозволяють зробити обґрунтований висновок про збереження в рідкому стані сплавів системи Ge-Mn-Gd сильної міжчастинкової взаємодії між різнойменними компонентами, яка властива системі Ge-Gd у твердому стані.

Список використаних джерел

1. Morozkin A. V., Seropegin Yu. D., Sviridov I. A. J. Alloy Compd. 1998. 269. L1-L5.

2. Narasimhan K. S. V. L., Rao V. U. S., Bergner R. L., Wallace W. E. J. Appl. Phys. 1975. 46(11). 4957-4960.

3. Kobayashi H., Onodera H., Yamamoto H., J. Magn. Magn. Mater. 1989. 79(1). 76-80.
3. Szytuła A., Wawrzyńska E., Penc B., Stüsser N., Tomkowicz Z., Zygmunt A. J. Alloy Compd. 2004. 367(1-2). 224-229.

5. Duijn H. G. M., Brück E., Buschow K. H. J., de Boer F. R. J. Magn. Magn. Mater. 1999. 197. 691-693.

6. Zhong X. C., Min J. X., Zheng Z. G., Liu Z. W., Zeng D. C. J. Appl. Phys. 2012. 112. 033903. 1-5.

7. Kanibolotsky D. S., Kotova N. V., Bieloborodova O. A., Lisnyak V. V. J. Chem. Thermodyn. 2006. 38. 849-860.

8. Kotova N. V., Usenko N. I., Golovata N. V. French-Ukr. J. 2019. 7(2). 68-79. 9. Головата Н., Котова Н., Усенко Н. Вісн. Київ. нац. ун-ту імені Тараса Шевченка. Хімія. 2017. 1(53). 69-71.

Golovata N., Kotova N., Usenko N. Visnyk Kyivs'koho natsional'noho universytetu imeni Tarasa Shevchenka. Khimiia. 2017. 1(53). 69-71 (In Ukrainian).

10. Berche A., Tedenac J. C., Jund P. Intermetallics, 47. 2014. 23-30.

11. Geld P. V., Petrushevsky M. S., Yesin Yu. O., Gorbunov Yu. V. Dokl. Akad. Nauk SSSR. 1974. 217. 1114-1117.

12. Beloborodova E. A. B., Kazymyrov V. P., Batalyn H. Y. Zh. Fiz. Khim. 1977. 51. 7. 1800-1801.

13. Kanibolotsky D. S., Golovata N. V., Bieloborodova O. A., Lisnyak V. V. J. Chem. Thermodyn. 2005. 37. 117-129.

14. Okamoto H. J. Phase Equilib. Diff. 2012. 33(2). 163.

15. Sudavtsova V. S., Shevchenko M. A., Kotova N. V., Romanova L. A. Russ. J. Phys. Chem. 2011. 85. 1-8.

16. Горбачук М. П. Термодинамічні властивості силіцидів та германідів рідкісноземельних металів. Автореферат дис. ... д-ра хім. наук. Київ, 2016. 38 c.

Horbachuk M. P. Thermodynamic properties of silicides and germanides of rareearth metals. Abstract of thesis for doctor of science degree. Kyiv, 2016. 38 p.

17. Sudavtsova V. S., Kotova N. V. Inorg. Mater. 2007. 43. 567-572.

18. Wang J., Lin Sh., Rong M., Rao G., Zhou H. J. Therm. Anal. Calorim. 2017. 128. 2. 1009-1018.

19. Ivanov M., Berezutski V., Usenko N. Int. J. Mater. Res. (formerly Z. Metallkd.). 2011. 102(3). 277-281.

20. Kim J., Jung I.-H. Can. Metall. Quart. 2013. 52(3). 311-320.

Надійшла до редколегії 19.06.19 
Н. Головатая, канд. хим. наук,

golovatanataliya@gmail.com,

Н. Котова, канд. хим. наук,

Н. Усенко, канд. хим. наук,

Киевский национальный университет имени Тараса Шевченко, Киев, Ураина

\section{МОДЕЛИРОВАНИЕ ТЕРМОДИНАМИЧЕСКИХ СВОЙСТВ РАСПЛАВОВ ТРОЙНОЙ СИСТЕМЫ Ge-Mn-Gd}

Проанализированы существующие и рассчитаны термодинамические свойства жидких сплавов граничных двойных систем, образующих тройную Ge-Mn-Gd; определены энергии Гиббса смешения жидких сплавов системы Ge-Mn-Gd. Для определения активностей компонентов, энергий Гиббса смешения и энтальпий смешения жидких сплавов систем Ge-Mn(Gd), сплавообразование которых сопровождается значительным выделением тепла, была применена модель идеального ассоциированного раствора. Для расплавов системы Mn-Gd, взаимодействие в которых характеризуется довольно незначительными экзотермическими эффектами, использована модель регулярных растворов. На базе полученных для граничных двойных систем концентрационных зависимостей энергий Гиббса смешения определена поверхность энергии Гиббса смешения расплавов тройной системы Ge-Mn-Gd по модели регулярного раствора с привлечением метода Редлиха - Кистера - Мугеиану. Проведено сравнение полученной топологии проекций изолиний энергий Гиббса с установленными нами ранее термохимическими свойствами жидких сплавов этой системы. Сравнительный анализ вида этих поверхностей в системе Ge-Mn-Gd позволил сделать вывод, что поверхности $\Delta G$ и $\Delta_{m} H$ монотонно уменьшаются в направлении от марганцевого угла диаграммы к стороне треугольника Ge-Gd. Минимальному значению термодинамических характеристик смешения тройных жидких сплавов соответствует состав, совпадающий с составом наиболее стойкого тугоплавкого интерметаллида в системе Ge-Gd. По виду хода изолиний энергий Гиббса и интегральных энтальпий смешения можно сделать также вывод о влиянии упорядочения, существующего в системе Ge-Mn при мольной доле марганца более 0,7, на свойства тройных расплавов, расположенных вблизи этой бинарной системы. Таким образом, топология изолиний и значительные экзотермические значения полученных термодинамических величин позволяют сделать обоснованный вывод о сохранении в жидком состоянии сплавов системы Ge-Mn-Gd сильного межчастичного взаимодействия между разноименными компонентами, которое свойственно системе Ge-Gd в твердом виде.

Ключевые слова: марганеи, гадолиний, германий, жидкие сплавы, энергия Гиббса смешения, модель идеального ассоциированного раствора, модель регулярных растворов, метод Редлиха - Кистера - Муггиану, энтальпия смешения.

N. Golovata, PhD,

golovatanataliya@gmail.com,

N. Kotova, PhD

N. Usenko, PhD,

Taras Shevchenko National University of Kyiv, Kyiv, Ukraine

\section{MODELING OF THERMODYNAMIC PROPERTIES OF THE MELTS OF TERNARY Ge-Mn-Gd SYSTEM}

In the present work, the Gibbs energies of mixing of liquid alloys of the Ge-Mn-Gd ternary system were determined, which was made on the basis of an analysis of published data on the thermodynamic properties of liquid alloys of boundary binary systems that form the ternary Ge-Mn-Gd, as well as on the basis of the model calculations in these binary systems. To determine the activities of the components, the Gibbs energies of mixing, and the enthalpies of mixing of liquid alloys of the Ge-Mn(Gd) systems, for which alloying process is accompanied by significant heat release, an ideal associated solution model was applied. For the melts of the Mn-Gd system, which are characterized by rather insignificant exothermic effects, a model of regular solutions was used. The surface of the Gibbs energy of mixing for the alloys of the Ge-Mn-Gd ternary system has been determined on the basis of the concentration dependences of the Gibbs energies of mixing obtained for constituent binary systems under the assumption of additivity of pair interactions using the Redlich-Kister-Muggianu method. The obtained topology of the Gibbs energy isolines projections is compared with the thermochemical properties of liquid alloys of this system that we have determined earlier. A comparative analysis of the topology of these surfaces in the Ge-Mn-Gd system led to the conclusion that the surfaces of $\Delta G$ and $\Delta_{m} H$ monotonically decrease from the manganese-rich angle of the diagram towards the Ge-Gd side of the concentration triangle. The minimum value of the thermodynamic characteristics of mixing of the ternary liquid alloys corresponds to the composition, which coincides with the composition of the most stable intermetallic compound in the Ge-Gd system. From the course of isolines of free energies and integral enthalpies of mixing, one can also conclude about the influence of a short-range order, existed in the Ge-Mn system near the composition with a mole fraction of mangan greater than 0.7 , on the properties of ternary alloys in the vicinity of this composition. Thus, the topology of isolines and the large exothermic values of the obtained thermodynamic properties allow us to make a reasonable conclusion that the strong interaction between unlike components inherent in the Ge-Gd system in the solid state is also maintained for liquid alloys of the Ge-Mn-Gd system.

Keywords: manganese, gadolinium, germanium, liquid alloys, Gibbs energy of mixing, ideal associated solution model, regular solution model, Redlich-Kister-Muggianu method, mixing enthalpy.

УДК 547.1-32-304.2, 547.821.2

DOI: https://doi.org/10.17721/1728-2209.2019.1(56).5

С. Шилін, канд. хім. наук, varang77@ukr.net,

3. Войтенко, д-р хім. наук,

М. Нечай, студ.,

Київський національний університет імені Тараса Шевченка, Київ Україна

\section{СИНТЕТИЧНІ ПІРИДИНОВМІСНІ АМІНОКИСЛОТИ ТА ÏХНІ ПОХІДНІ}

В умовах перегрупування Шмідта дією азиду натрію на основі циклопентанону та циклогексанону із 2-піридиновим замісником у положенні а отримано 2-піридилзаміщені ү- та є-лактам, відповідно. Унаслідок кислотного гідролізу утворених лактамів отримано нові амінокислоти: відповідно 5-аміно-5-(піридин-2-іл)пентанову та 6-аміно-6-(піридин-2-іл)гексанову. Указані кислоти було вилучено й охарактеризовано як у формі гідрохлоридів, так і у вигляді електронейтрального цвітер-іона.

Ключові слова: синтетичні ठ- та в-амінокислоти, перегрупування Шмідта, піколіл-2-амін.

Амінокислоти та їхні похідні є надзвичайно важливим класом природних сполук, що беруть участь у життєдіяльності будь-якого організму. Більшість із них $\epsilon$-амінокислотами, але знайдені такі структури цього класу, в яких аміногрупа значно віддалена від карбоксильної групи. Прикладами таких речовин є $\varepsilon$-амінокапронова кислота, яка викликає специфічну кровоспинну дію при кровотечах, пов'язаних із підвищенням фібринолізу (розчинення згустку крові), та ү-аміномасляна кислота, що $\epsilon$ гальмівним нейромедіатором у центральній нервовій системі. Із основною інформацією про шляхи отримання та застосування зазначених препаратів можна ознайомитися у книзі [1]; у тому ж виданні наведено приклади лікарських засобів на основі синтетичних аналогів вказаних амінокислот.

Також відомою є важлива роль, яку в сучасній медицині відіграють сполуки з піридиновим або піперидиновим ядром. Більше $10 \%$ найбільш розповсюджених 